\title{
Decay-accelerating Factor Protects Human Tumor Cells from Complement-mediated Cytotoxicity In Vitro
}

\author{
Nai-Kong V. Cheung, * Elizabeth I. Walter, William H. Smith-Mensah, William D. Ratnoff, Mark L. Tykocinski, and \\ M. Edward Modof \\ Department of Pediatrics, ${ }^{*}$ Memorial Sloan Kettering Cancer Center, New York 10021; and Department of Pathology, Institute \\ of Pathology, University Hospitals of Cleveland, Ireland Cancer Center, Case Western Reserve University, Cleveland, Ohio 44106
}

\begin{abstract}
The disialoganglioside $\mathbf{G}_{D_{2}}$ is expressed on a wide spectrum of human tumor types, including neuroblastomas and melanomas. Upon binding of 3F8, a murine monoclonal antibody (MAb) specific for $\mathbf{G}_{\mathbf{D} 2}$, neuroblastomas and some melanomas are sensitive to killing by human complement, whereas some melanomas are not. To investigate the mechanism underlying these differences in complement mediated cytotoxicity, complementinsensitive melanoma cell lines were compared with respect to expression of the decay-accelerating factor (DAF), a membrane regulatory protein that protects blood cells from autologous complement attack. While DAF was undetectable among neuroblastomas, it was present in complement-insensitive melanomas. When the function of DAF was blocked by anti-DAF MAb, C3 uptake and complement-mediated lysis of the insensitive melanoma lines were markedly enhanced. $F(\mathbf{a b})_{2}$ fragments were as effective in enhancing lysis as intact anti-DAF MAb. The DAF-negative and DAF-positive melanoma cell lines were comparably resistant to passive lysis by cobra venom factor-treated serum. The data suggest that in some tumors, DAF activity accounts for their resistance to complement-mediated killing. The ability to render these cells complement-sensitive by blocking DAF function may have implications for immunotherapy.
\end{abstract}

\section{Introduction}

Studies in both experimental animals and human patients have suggested that complement activation can play a role in tumor cytotoxicity in vivo (reviewed by Podack [1]). In nude mice, injection of complement-reactive $\operatorname{IgM}$ and $\operatorname{IgG}_{2 \mathrm{a}}$, (but not complement-unreactive $\mathrm{IgG}_{1}$ ) monoclonal antibodies (MABs) against hepatitis B surface antigen suppresses the growth of xenografted human hepatomas (2), whereas the administration of $\operatorname{IgM}, \operatorname{IgG}_{2 a}$, or $\operatorname{IgG}_{3}$ complement-fixing tumor-specific antibodies induces regression of established human melanoma and breast tumors (3-5). In patients, injection of complement-fixing mouse MAbs directed against surface antigens of neuroblastomas and a variety of other tumor cell types have shown antitumor effects (6-8). $\mathrm{R} 24$, an $\mathrm{IgG}_{3}$ antibody, when infused into patients with malignant mela-

Address correspondence and reprint requests to Dr. Cheung, Pediatrics, Memorial Sloan-Kettering Cancer Center, 1275 York Avenue, New York, NY 10021.

Received for publication 11 March 1987 and in revised form 9 October 1987.

J. Clin. Invest.

(C) The American Society for Clinical Investigation, Inc. $0021-9738 / 88 / 04 / 1122 / 07 \quad \$ 2.00$

Volume 81, April 1988, 1122-1128 noma localizes at tumor site(s) and deposits $\mathrm{C} 4$ and $\mathrm{C} 3$ determinants (6). Recently, the tumorcidal effects of specific antitumor antibody and complement have been exploited to destroy malignant cells in vitro. Purging of bone marrow with antibodies and complement in vitro has been shown to eradicate leukemia cells $(9,10)$ as well as a number of solid tumors (11-13).

$G_{D 2}$ is a surface ganglioside expressed on a large number of malignancies including neuroblastomas, melanomas, sarcomas, and brain tumors. A series of MAbs specific for this oncofetal antigen has recently been described (14-16). In the presence of these antibodies, human complement is consistently effective in killing neuroblastoma lines in vitro (11). The ability of the monoclonal antibodies to effect this cytotoxicity is dependent on the presence of surface $G_{D 2}$ antigen, since normal marrow cells as well as other tumor cell types that lack $\mathrm{G}_{\mathrm{D} 2}$ are not damaged. Among melanomas, however, several cell lines have been identified which, despite binding of complement-fixing antibodies, are resistant to in vitro complement killing $(17,18)$. This finding has indicated that factors other than surface expression of target antigen must play a role in the susceptibility of these cells to complement-mediated cytotoxicity.

Decay-accelerating factor (DAF) ${ }^{1}$ is a cell membrane-associated inhibitor of complement activation $(19,20)$ which provides protection for blood cells from potential injury arising from attack by autologous complement proteins. By interfering with the assembly of autologous $\mathrm{C} 3(\mathrm{C} 4 \mathrm{~b} 2 \mathrm{a}$ and $\mathrm{C} 3 \mathrm{bBb}$ ), and $\mathrm{C} 5$ convertases (C4b2a3b and $\mathrm{C} 3 \mathrm{bBb} 3 \mathrm{~b})(20-22), \mathrm{DAF}$ blocks the amplification steps of both the classical and alternative complement pathways on host cell surfaces. DAF is present in the membranes of erythrocytes, platelets, neutrophils, monocytes, and lymphocytes $(23,24)$ as well as vascular endothelium (25), i.e., all cell types in intimate contact with serum complement proteins. Recent studies have shown that it is also present on epithelial cells lining extravascular compartments (26). The importance of DAF in protecting blood cells in vivo is indicated by the finding that its deficiency in patients with paroxysmal nocturnal hemoglobinuria (PNH) is causally related to the hemolytic anemia that is characteristic of this clinical disorder.

In this study we quantified the amount of DAF in various human tumor cell lines and examined the role of DAF activity in their susceptibility to in vitro complement-mediated cytotoxicity. We found that the inhibition of DAF function in certain complement-resistant tumors markedly increased their susceptibility to complement-mediated killing.

1. Abbreviations used in this paper: ADCC, antibody-dependent cellmediated cytotoxicity; DAF, decay-accelerating factor; IRMA, immunoradiometric assay; $\mathrm{PNH}$, paroxysmal nocturnal hemoglobinuria. 


\section{Methods}

Complement and MAbs. Human complement was prepared from freshly collected human serum and frozen at $-70^{\circ} \mathrm{C}$. Thawed aliquots were diluted in Hanks' balanced salt solution (HBSS) (Gibco, Grand Island, NY) for the complement cytotoxicity assays. The following antibodies were obtained as previously described: $3 \mathrm{~F} 8$, an $\mathrm{IgG}_{3}$ specific for the disialoganglioside $G_{D_{2}}(14)$, IA $10\left(\operatorname{IgG}_{2 a}\right)$, IIH6 $\left(\operatorname{IgG}_{1}\right)$, and VIIIA7 $\left(\mathrm{IgG}_{1}\right)$ specific for DAF (21). Control murine MAbs, L243 $\left(\operatorname{IgG}_{2 \mathrm{a}}\right.$ anti-Ia), W6/32 (IgG $2 \mathrm{a}$ anti-HLA-ABC), and BB7.5 (IgG anti-HLA-ABC monomorphic determinant) were purchased from the American Type Culture Collection (ATCC), Bethesda, MD. R24, an $\mathrm{IgG}_{3}$ murine antibody specific for the disialoganglioside $G_{D 3}$ was provided by Dr. A. Houghton of Memorial Sloan-Kettering Cancer Center, New York. $F\left(a^{\prime}\right)_{2}$ fragments were prepared by digestion of MAbs for $5 \mathrm{~h}$ at $37^{\circ} \mathrm{C}$ with $2 \%$ (wt/wt) pepsin (Sigma Chemical Co., St. Louis, MO) in acetate buffer, $\mathrm{pH} 4$, and then purified on a Superose-12 column in $0.05 \mathrm{M}$ phosphate-buffered saline, pH 7.2, using FPLC (Pharmacia Fine Chemicals, Piscataway, NJ). Complement C3 was provided by Dr. C. Mold, University of New Mexico, Albuquerque, and prepared as previously described. Cobra venom factor was purified and used to activate serum according to the method of Parker et al. (27).

Cell lines. The following tumor cell lines were obtained from the ATCC: IMR32, SKNMC, SKMel-1, HT144, Malme-3A, SKMel-28, SKMel-5, HeLa, BT-20, MCF-7, SK-BR-1 III, MDA-MB-134-VI, MDA-MB-157, MDA-MB-175-VII, and NCI-H69. The cell lines LAN-1, LAN-2, and LAN-5 were kindly provided by Dr. R. Seeger of University of California, Los Angeles. The cell lines NMB-7 and IMR-6 were obtained from Dr. R. K. Liao of McMaster University, Hamilton, Ontario, Canada. The melanoma cell line SKMel-31 was provided by Dr. A. Houghton of Memorial Sloan-Kettering Cancer Center. The small cell lung CA lines were provided by Dr. A. Gazdar of the National Cancer Institute, Bethesda, MD and Dr. H. Lazarus of University Hospitals of Cleveland, $\mathrm{OH}$. The melanoma cell lines Mel-101 and Mel-102 were established in our laboratory. All cell lines were cultured in $10 \%$ heat-inactivated calf serum (CS) (HyClone Laboratories, Logan, UT) in RPMI 1640.

Analytical methods. SDS-PAGE was carried out according to the method of Laemmli (28). The two-site immunoradiometric assay (IRMA) for DAF contents of cell extracts has been previously described (23).

Indirect immunofluorescence. Flow cytometry was performed using a cytofluorograph 2S (Ortho Diagnostics Inc., Westwood, MA) by indirect immunofluorescence. Cells were prepared and stained as described (14), employing a single MAb 3F8, for the quantitation of $G_{D 2}$. Pooled MAbs (IA 10/IIH6/VIIIA7 = 20:20:1) were used for quantitation of DAF and corresponding monoclonals of the same subclasses were utilized as controls (23).

Complement-mediated tumor cytotoxicity assay. Target tumor cells were washed in $5 \%$ heat-inactivated $\left(56^{\circ} \mathrm{C}\right.$ for $\left.30 \mathrm{~min}\right)$ calf serum in HBSS and labeled with ${ }^{51} \mathrm{Cr}$ (Amersham Corp., Arlington Heights, IL) at $100 \mu \mathrm{Ci}$ per million cells at $37^{\circ} \mathrm{C}$ for $1 \mathrm{~h}$. After washing, loosely bound ${ }^{51} \mathrm{Cr}$ was leaked for $1 \mathrm{~h}$ at $37^{\circ} \mathrm{C}$ and after further washing, the cells were added at $10^{4}$ cells per well in 96-well polystyrene round-bottom plates (Becton-Dickinson, San Diego, CA). Cytotoxic antibody was added to a final concentration of $100 \mu \mathrm{g} / \mathrm{ml}$ followed by human serum to a final concentration of 1:8 (unless otherwise indicated). Each well contained a total volume of $250 \mu$ of medium that contained cells, antibody, and complement. The plates were incubated at $37^{\circ} \mathrm{C}$ for $2 \mathrm{~h}$, and then centrifuged at $1,000 \mathrm{rpm}$, and the released ${ }^{51} \mathrm{Cr}$ in supernatants was counted in a gamma counter (Packard Instrument Co., Inc., Downers Grove, IL). Percent specific release was calculated using the formula: $100 \% \times($ experimental cpm - background cpm)/(10\% SDS cpm - background cpm), where cpm are the counts per minute of ${ }^{51} \mathrm{Cr}$ released. Total release was assessed by lysis with $10 \%$ SDS (Sigma Chemical Co.) and background release was measured in the absence of complement.
Antibody-dependent cell-mediated tumor cytotoxicity (ADCC). Target cells were prepared as described above. Peripheral blood mononuclear cells obtained by Ficoll-Paque gradient were used as effector cells at various effector/target ratios in a standard 4-h ${ }^{51} \mathrm{Cr}$-release assay. Percent specific release was calculated using the same formula as was used for complement cytotoxicity. Total release was obtained by lysis with $10 \%$ SDS, and background lysis was assessed in the absence of effector cells.

Radiolabeling and quantitation of C3 uptake. C3 was labeled with ${ }^{125}$ I using Iodogen (Pierce Chemical Co., Rockford, IL) according to the manufacturer's instructions. Unreacted iodide was removed by gel filtration through G-25 (Pharmacia Fine Chemicals).

To determine the amount of C3b uptake, $200 \mu \mathrm{l}$ of $10^{5}$ tumor cells/ml were mixed with $50 \mu \mathrm{l}$ of $500 \mu \mathrm{g} / \mathrm{ml}$ of $3 F 8$ and $200 \mu \mathrm{l}$ of 1:8 dilution of human serum containing $10^{6} \mathrm{cpm}$ of radiolabeled $\mathrm{C} 3$. The reaction mixture was incubated at $37^{\circ} \mathrm{C}$ and stopped by centrifugation and cooling to $4^{\circ} \mathrm{C}$ at various times between 0 and $90 \mathrm{~min}$. Cell pellets were counted in a gamma counter. Calculations of the amount of $\mathrm{C} 3$ bound per cell were based on a normal $\mathrm{C} 3$ concentration in undiluted human serum of $1.4 \mathrm{mg} / \mathrm{ml}$. A molecular mass of 175,000 daltons was used for the calculation of the number of $\mathrm{C} 3 \mathrm{~b}$ molecules per cell.

Reactive lysis. ${ }^{51} \mathrm{Cr}$-labeled tumor cells in serial dilutions (1:4 to $1: 256)$ of human serum were incubated at $37^{\circ} \mathrm{C}$ for $1 \mathrm{~h}$ with preformed cobra venom factor $\mathrm{Bb}$ complexes as previously described (29). After dilution with ice-cold buffer and centrifugation, percent ${ }^{51} \mathrm{Cr}$ release was measured.

\section{Results}

Quantitation of DAF levels in tumor cell lines. Total DAF contents of various tumor cell lines as measured by two-site IRMA employing anti-DAF monoclonals are shown in Table I. Levels of DAF in normal blood elements established in previous studies (23) are shown for comparison. DAF levels in tumor cell lines varied from $<0.1 \mathrm{ng} / 10^{7}$ cells (corresponding to $<100$ DAF molecules per cell) to $53 \mathrm{ng} / 10^{7}$ cells $(45,600$ molecules per cell). Among neuroblastoma and small cell lung carcinoma cell lines, none contained detectable levels of DAF. In other tumor types, levels in individual lines were nonuniform. Among melanomas, SKMel-1 showed no DAF whereas HT-144, SKMel-28, and SKMel-31 showed levels in the lower range of nucleated blood cells.

Comparative complement sensitivity of DAF-positive and -negative melanoma lines. To study the functional significance of DAF expression by tumor cells, two $\mathrm{G}_{\mathrm{D} 2}$-positive melanoma lines (HT-144 and SKMel-1), which differed with respect to the absence or presence of DAF, were selected for analysis. FACS analyses (Fig. 1) showed that the HT-144 and SKMel-1 lines were both strongly positive for $G_{D 2}$ and, with respect to this antigen, exhibited cell populations with comparable mean fluorescence. In contrast, when examined for surface DAF, SKMel-1 cells were nearly or totally DAF negative, whereas HT144 cells were uniformly positive (Fig. 1).

The sensitivities of the two cell lines to complement-mediated cytotoxicity were next compared in ${ }^{51} \mathrm{Cr}$-release assays. Irrespective of the dilution of complement (serum) used (Fig. 2 $A$ ) and the concentration of the $\mathrm{G}_{\mathrm{D}^{2} \text {-sensitizing antibody em- }}$ ployed (data not shown), HT144 cells exhibited nearly complete resistance to complement killing. In contrast, under identical conditions, SKMel-1 cells were readily killed, even at a 1:32 dilution of complement (serum).

To determine if the greater lytic susceptibility of the SKMel-1 line is a nonspecific characteristic of this tumor 
Table I. DAF Contents of Normal Tissues and Various Tumor Cell Lines

\begin{tabular}{|c|c|}
\hline Cells & DAF molecules per cell \\
\hline \multicolumn{2}{|l|}{ Normal* } \\
\hline Erythrocytes & 3,300 \\
\hline Platelets & 2,100 \\
\hline PMN & 85,000 \\
\hline Monocytes & 67,900 \\
\hline Lymphocytes & 32,800 \\
\hline \multicolumn{2}{|l|}{ Neuroblastoma } \\
\hline LAN-1 & $<100$ \\
\hline LAN-2 & $<100$ \\
\hline LAN-5 & $<100$ \\
\hline NMB-7 & $<100$ \\
\hline IMR-6 & $<100$ \\
\hline IMR-32 & $<100$ \\
\hline \multicolumn{2}{|l|}{ Melanoma } \\
\hline HT-144 & 14,600 \\
\hline SK-Mel-31 & 10,500 \\
\hline SK-Mel-28 & 3,200 \\
\hline SK-Mel-5 & 350 \\
\hline SK-Mel-1 & $<100$ \\
\hline Malme-3A & $<100$ \\
\hline Mel-101 & $<100$ \\
\hline Mel-102 & $<100$ \\
\hline \multicolumn{2}{|l|}{ Breast carcinoma } \\
\hline BT-20 & 45,700 \\
\hline MCF-7 & 21,800 \\
\hline SKBR-1 III & 17,200 \\
\hline MDA-MB-134-VI & $<100$ \\
\hline MDA-MB-157 & $<100$ \\
\hline MDA-MB-175-VII & $<100$ \\
\hline \multicolumn{2}{|c|}{ Small cell carcinoma of lung } \\
\hline NCI-H69 & $<100$ \\
\hline HCI-H128 & $<100$ \\
\hline NCI-H146 & $<100$ \\
\hline NCI-H209 & $<100$ \\
\hline
\end{tabular}

* Kinoshita et al. (23).

rather than a reflection of a specific difference in response to complement, the two cell lines were compared in their susceptibility in ADCC. In contrast to the results obtained in the complement assays, in ADCC the HT-144 and SKMel-1 cell lines exhibited equivalent cytotoxicity. The comparable extent of ${ }^{51} \mathrm{Cr}$ release in ADCC indicated that the sensitivity of SKMel-1 cells to complement did not derive from an increased fragility of the membranes of these cells and likewise that the lack of lysis of HT-144 in complement assays was not a result of the inability of this cell type to release chromium when killed (Fig. $2 B$ ).

Role of DAF activity in resistance of $H T-144$ cells to complement-mediated lysis. In order to establish whether the complement resistance of HT144 cells compared to that of SKMel-1 cells is a consequence of DAF action, the effect on

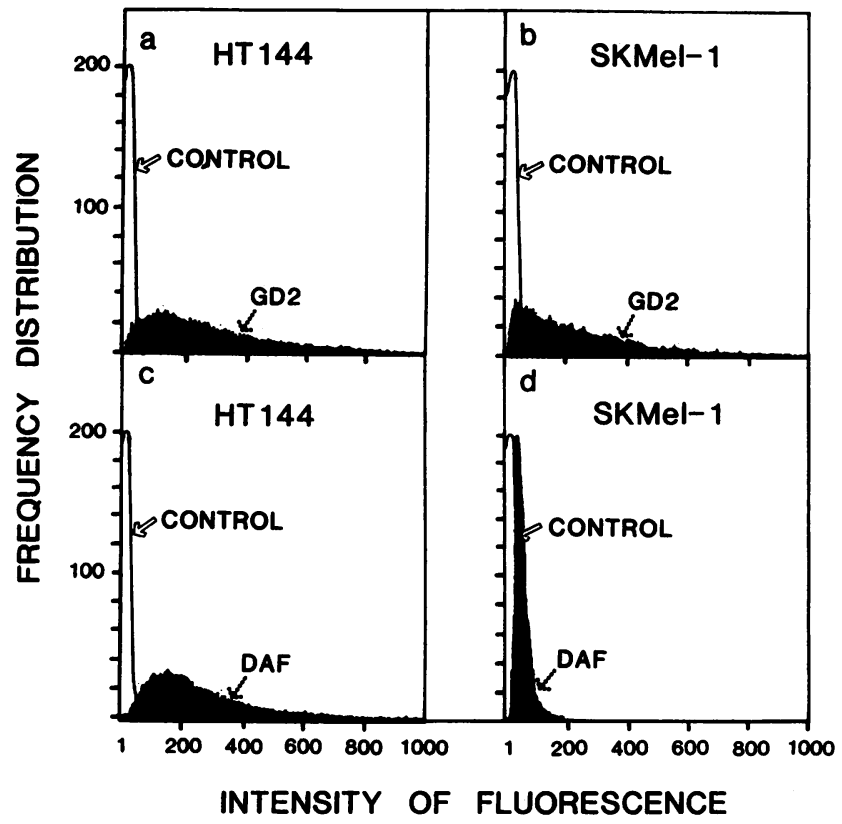

Figure 1. Expression of the tumor-associated antigen $\mathrm{G}_{\mathrm{D} 2}$ and of surface DAF on HT-144 and SKMel-1 melanoma cell lines. The cells were stained as described in Methods and the histograms were obtained by FACS analyses. The frequency of antigen-positive cells is shown as a function of the intensity of fluorescence. Surface $G_{D 2}$ was measured using antibody $3 \mathrm{~F} 8$, and surface DAF using pooled antiDAF MAbs. Control antibodies were IgG subclass-matched nonrelevant murine MAbs.

complement cytotoxicity and complement $\mathrm{C} 3$ deposition by blocking DAF function (21) in the HT-144 cells was assessed. ${ }^{51}$ Cr-labeled HT-144 target cells were preincubated for $30 \mathrm{~min}$

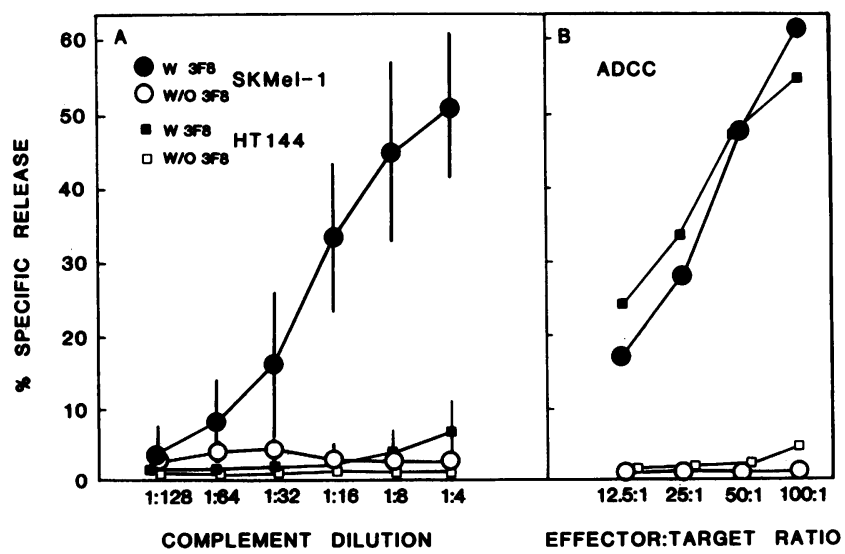

Figure 2. Comparative sensitivities of the HT-144 and SKMel-1 melanoma cell lines to complement-mediated and cell-mediated lysis. Percent specific ${ }^{51} \mathrm{Cr}$ release is shown as a function of complement dilution $(A)$ and effector/target cell ratio $(B)$. $(A)$ Complement-mediated lysis using normal human serum as a complement source and 3F8 as the antibody. (B) Antibody-dependent cell-mediated cytotoxicity using normal human peripheral blood mononuclear cells as effectors and 3F8 as the antibody. (๑) SKMel-1 in the presence of 3F8; (0) SKMel-1 in the absence of 3F8; (b) HT144 in the presence of 3F8; () HT144 in the absence of 3F8. 
with increasing concentrations of pooled anti-DAF MAbs. An aliquot of the anti-DAF-treated cells was then tested for lysis by the addition of 3F8 followed by human complement. As a control, another aliquot of the anti-DAF-pretreated cells was incubated with complement in the absence of 3F8. As additional controls, in place of anti-DAF monoclonals, ${ }^{51} \mathrm{Cr}$-labeled HT-144 target cells were preincubated with either $(a)$ anti-Ia (L243), (b) anti-HLA-ABC (W6/32), (c) anti-HLA monomorphic (BB7.5) MAbs, or $(d)$ medium alone and then tested as above with $3 \mathrm{~F} 8$ followed by complement. As summarized in Fig. 3, only anti-DAF antibody preincubation sensitized the HT144 cells to complement-mediated lysis. Percent killing of the anti-DAF-treated HT144 cells approached that of the complement-sensitive cell line SKMel-1. Insignificant killing of the anti-DAF-treated cells occurred in the absence of 3F8 or when anti-Ia or anti-HLA-ABC MAbs (of corresponding subclasses) were substituted for anti-DAF MAbs. To verify that these control monoclonals were in fact binding to the cells, flow cytometric analyses of antibody-treated cells were performed. These results showed that L243, W6/32, and BB7.5 bound to surface antigens on HT-144 cells in comparable amounts to the anti-DAF antibodies (Table II). The enhancing effect of anti-DAF pretreatment on HT-144 cell killing at different complement dilutions is shown in Fig. 4. At all complement concentrations, augmentation by anti-DAF antibodies of complement sensitivity of the HT-144 cells was dose dependent.

Despite the inability of pooled anti-DAF MAbs alone (Fig. $2 A$ ) or of the above control MAbs in conjunction with 3F8 (Fig. 3) to induce complement cytotoxicity, additional experiments were performed to rule out the elicitation of a cooperative effect between the anti-DAF monoclonals and 3F8 in activating complement. For this purpose, the pooled antiDAF MAbs were digested with pepsin and anti-DAF $F\left(a b^{\prime}\right)_{2}$ fragments isolated. Analysis of the products of the digestions on SDS-PAGE showed bands at 29 and $27 \mathrm{kD}$ consistent with the presence of $F\left(a b^{\prime}\right)_{2}$ fragments exclusively. No bands corresponding to uncleaved $\mathrm{H}$-chains $(51 \mathrm{kD})$ were observed in the gels and no intact IgG molecules were detectable by chromatography on Superose-12. Substitution of the pooled antiDAF $\mathrm{F}\left(\mathrm{ab}^{\prime}\right)_{2}$ for intact antibodies in the complement cytotoxicity assays using HT-144 cells resulted in comparable en-

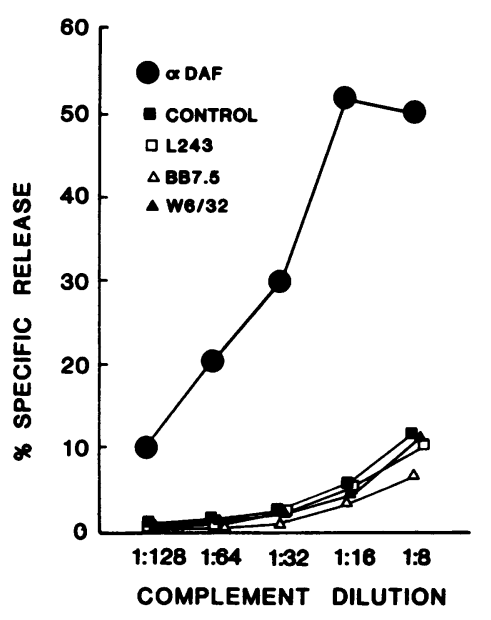

Figure 3. Effect of blocking of DAF function on complement-mediated cytotoxicity of the HT-144 melanoma line. Target cells were preincubated with pooled anti-DAF MAbs (•), antibodies L243 (ם), BB7.5 $(\Delta)$, and W6/32 ( $\Delta)$ or medium ( $(\mathbf{)}$, and then tested in the complement lysis assay in the presence of antibody $3 F 8$. Percent specific ${ }^{51} \mathrm{Cr}$ release is shown as a function of complement dilution.
Table II. Flow Cytometric Analysis of Binding of Different Monoclonal Antibodies to HT-144 Cells

\begin{tabular}{llc}
\hline \multicolumn{1}{c}{ Antibody name } & \multicolumn{1}{c}{ Specificity } & $\begin{array}{c}\text { Mean fluorescence } \\
\text { intensity } \\
\text { (channel number) }\end{array}$ \\
\hline Control supernatant & \multicolumn{1}{c}{-} & 17 \\
L243 & Anti-Ia & 286 \\
W6/32 & Anti-HLA-ABC & 135 \\
BB7.5 & Anti-HLA-monomorphic & 97 \\
IA10, IIH6, VIIIA7 & Anti-DAF & 172 \\
& & \\
\hline
\end{tabular}

hancement of killing (Fig. 5). Quantitative dose response experiments (Fig. 6) showed that the pooled $F\left(a b^{\prime}\right)_{2}$ and pooled anti-DAF IgG functioned with virtually equivalent efficiency.

When the deposition of $\mathrm{C} 3$ on these cells was studied, a peak level of 298,000 molecules of $\mathrm{C} 3 \mathrm{~b}$ per cell was observed (1:16 serum, $15 \mathrm{~min}$ at $37^{\circ} \mathrm{C}$ ) for SKMel-1 in the presence of 3F8. In contrast, only 69,000 molecules were deposited on HT-144. However, when DAF function in HT-144 cells was blocked by preincubation with anti-DAF antibodies, peak uptake of C3b on these cells rose to 269,000 molecules per cell.

In order to determine if the difference in complement sensitivities of the two melanoma lines could derive from differences in the function of homologous restriction factor, in addition to differences in DAF, the SKMel-1 and HT-144 cell lines were tested in reactive lysis using cobra venom factortreated serum. In contrast to type III PNH human erythrocytes, which showed $30 \%$ lysis in 1:256 dilution of serum and $>80 \%$ lysis in 1:64 serum, both tumor types gave $<5 \%$ lysis in 1:4 serum (data not shown). When DAF function of HT-144 was blocked by preincubation with anti-DAF antibodies, no increase in the lysis of the cells in cobra venom factor-treated serum was observed.

Role of DAF activity in complement resistance of other melanomas. To exclude the possibility that HT144 cells or that $G_{D 2}$ antigen have unique properties in complement activation

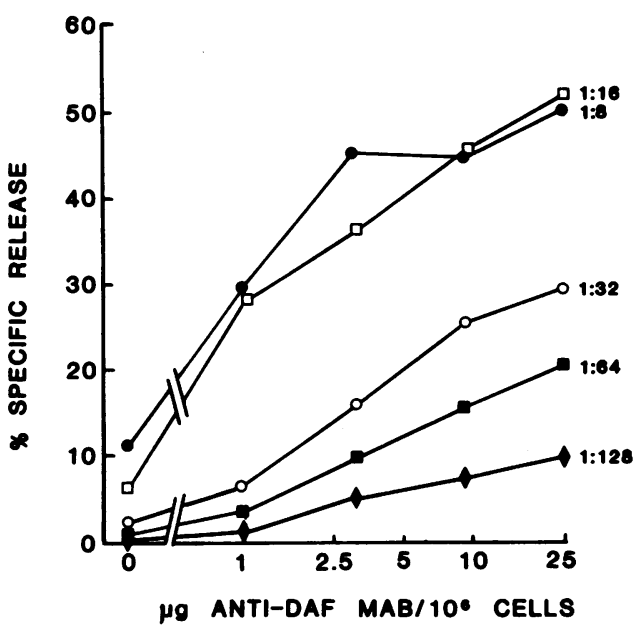

Figure 4. Dose dependence of the effect of anti-DAF antibodies in sensitization of tumor cells to complement-mediated cytotoxicity. Percent specific ${ }^{51} \mathrm{Cr}$ release is shown as a function of the micrograms of anti-DAF antibodies added per $10^{6}$ cells. Human complement was used at increasing dilutions (1:8 to $1: 128)$. 


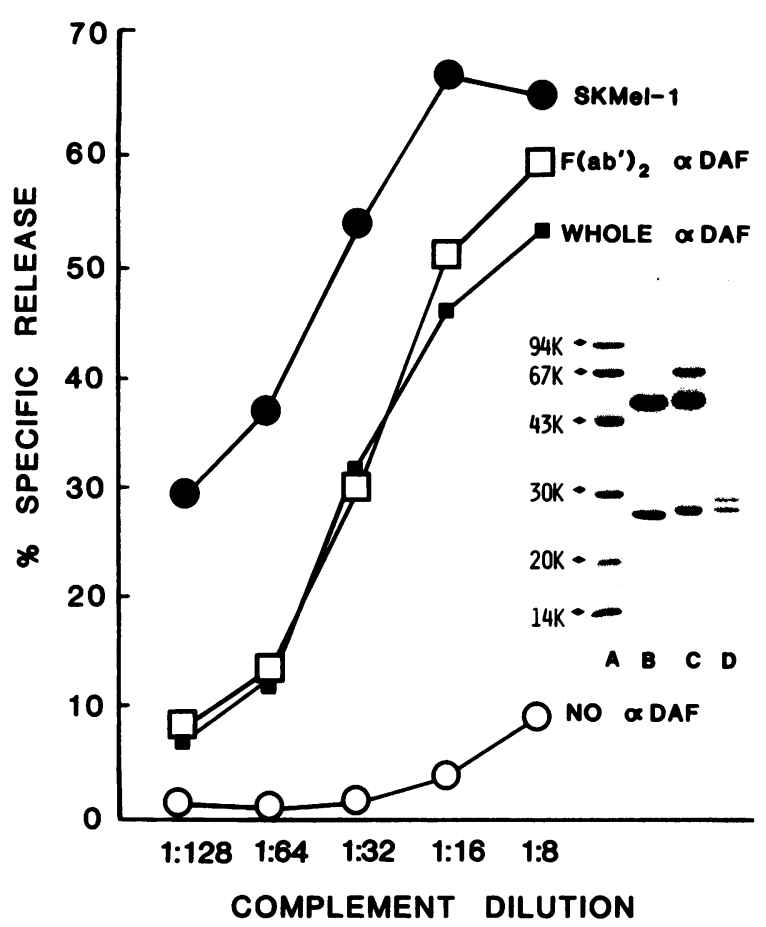

Figure 5. Comparative effects of intact and $\mathrm{F}\left(\mathrm{ab}^{\prime}\right)_{2}$ anti-DAF MAb in blocking DAF function in HT-144 cell line. ${ }^{51} \mathrm{Cr}$-labeled HT144 was cells were preincubated with whole anti-DAF antibody ( $(0)$, antiDAF $F\left(a^{\prime}\right)_{2}$ fragments ( $\square$ ), or control medium (O), respectively. ( $\bullet$ ) The DAF negative cell line SKMel-1 assayed under similar conditions without anti-DAF antibodies. (Inset) SDS-PAGE analysis of the untreated anti-DAF antibody (lane $C$ ), the anti-DAF $\mathrm{F}\left(\mathrm{ab}^{\prime}\right)_{2}$ fragment (lane $D$ ), and the antibody 3F8 (lane $B$ ) together with the molecular mass standards (lane $A$ ). In lane $C$, three bands corresponding to albumin, heavy chain, and light chain are apparent. In lane $D$, only two bands corresponding to $F\left(\mathrm{ab}^{\prime}\right)$ and light chain are seen.

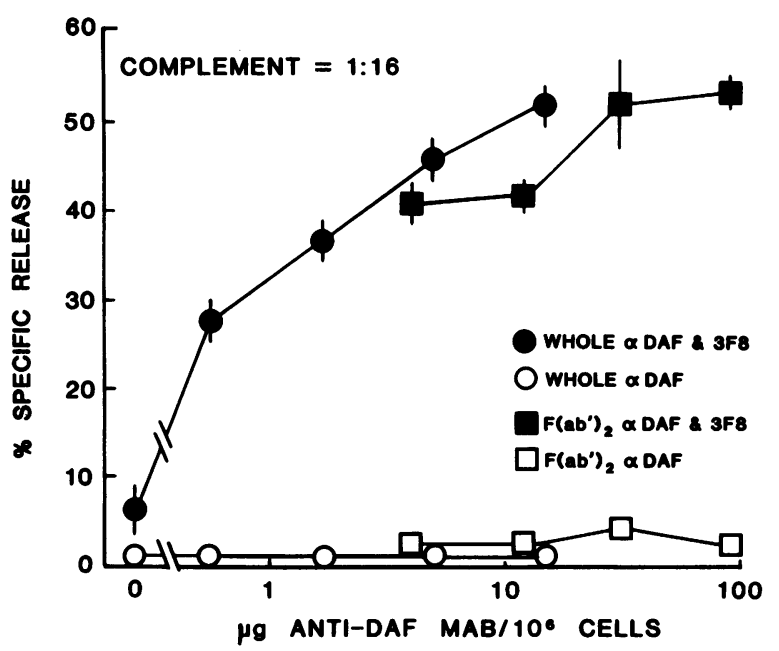

Figure 6. Comparative dose dependence of the effects of intact and $F\left(a b^{\prime}\right)_{2}$ anti-DAF antibodies in blocking DAF function in HT-144 melanoma cells. Percent ${ }^{51} \mathrm{Cr}$ release is shown as a function of $\mu \mathrm{g}$ antibody added per $10^{6}$ HT- 144 cells. HT- 144 cells preincubated with intact anti-DAF MAb were assayed for susceptibility to lysis in the presence $(\bullet)$ or absence $(0)$ of $3 F 8$. Cells preincubated with $F\left(a^{\prime}\right)_{2}$ anti-DAF MAb were similarly tested in the presence $(a)$ and absence () of 3F8. and to investigate whether the observation with HT-144 cells concerning DAF function also apply to other tumor lines and tumor antigens, SKMel-31 and SKMel-28 melanoma lines (10,500 and 3,200 DAF molecules per cell; Table I) were substituted for HT-144 cells and the experiments with anti-DAF antibodies were repeated. For studies with SKMel-28 cells (which express $G_{D 3}$ rather than $G_{D 2}$ ), R24, a murine $I_{g G}$ anti- $G_{D_{3}}$ MAb, was substituted for $3 F 8$. When DAF function in the SKMel-31 and SKMel-28 lines were blocked under conditions identical to those used in the experiments with HT-144, enhanced cytotoxicity similar to that found in HT-144 cells was observed (Table III).

\section{Discussion}

The experiments described in this report demonstrate that the susceptibility of tumor cells to complement-mediated cytotoxicity can be modulated by surface DAF expression of the cells. Analyses of assorted tumor lines by IRMA employing antiDAF MAbs revealed that DAF levels can vary widely among different tumor types as well as among individual lines within the same tumor type (Table I). Neuroblastomas and small cell lung carcinomas were found to be uniformly devoid of DAF protein. This finding correlates with previous observations $(8$, 30) that these tumor types are characteristically susceptible to killing in vitro by human complement in the presence of monoclonal antibody. In contrast, melanoma and breast tumor cell lines were found to contain levels of DAF varying from $<100$ to 45,700 molecules per cell, the latter value comparable to those on blood leukocytes (21). The variability of DAF levels in these tumor cell lines is in accordance with the antigenic and clinical heterogeneity encountered in these tumor types. Individual melanoma lines which were similar by some other criteria but differed with respect to the presence or absence of DAF (Table I, Fig. 1) exhibited complement sensitivity inversely correlating with their DAF contents (Fig. 2). When these melanomas were employed as model systems to investigate DAF action, blocking DAF function with antiDAF MAbs enhanced their susceptibility to complement-mediated lysis fully to the level of DAF-negative lines. Experiments with radiolabeled $\mathrm{C} 3$ showed differences in uptake of $\mathrm{C} 3$ by the two cell lines consistent with DAF's mechanism of

Table III. Complement-mediated Cytotoxicity

of Tumor Cell Lines in the Absence and Presence of Anti-DAF Monoclonal Antibodies

\begin{tabular}{lcccc}
\hline Cell line & $\begin{array}{c}\text { DAF molecules } \\
\text { per cell }\end{array}$ & $\begin{array}{c}\text { Cytotoxic } \\
\text { antibody* }\end{array}$ & Anti-DAF & $\begin{array}{c}\text { Specific } \\
\text { release }\end{array}$ \\
\hline \multirow{2}{*}{ HT144 } & 14,600 & $3 \mathrm{~F} 8$ & - & $\%$ \\
& & $3 \mathrm{~F} 8$ & + & 4.7 \\
SKMel-31 & 10,500 & $3 \mathrm{~F} 8$ & - & 49.0 \\
& & $3 \mathrm{~F} 8$ & + & 18.0 \\
SKMel-28 & 3,200 & R24 & - & 66.0 \\
& & R24 & + & 30.0 \\
SKMel-1 & $<100$ & $3 F 8$ & - & 79.0 \\
& & $3 F 8$ & + & 76.0 \\
& & & & \\
\hline
\end{tabular}

* Final concentration of human complement was 1:8 and final concentration of cytotoxic antibody was $100 \mu \mathrm{g} / \mathrm{ml}$. 
action. In addition, studies with cobra venom factor serum showed that the differences in complement sensitivities of the two melanoma cell lines were not attributable to different sensitivities to C5b-9 and thus to differences in expression of homologous restriction factor, another protein restricting the sensitivity of host cells to autologous complement attack (31).

The mechanisms by which cells regulate DAF expression are not yet fully understood. It is possible that in certain cell types, DAF is not expressed or that DAF expression is a late differentiation event. Such a mechanism, in principle, could account for the finding that neuroblastoma lines are uniformly DAF negative, but might not as readily explain all the variability of DAF expression within different lines of other tumor types, i.e., melanoma and breast carcinomas. In cells that normally express DAF, neoplastic transformation could result in a failure to express DAF. This could arise from downregulation of DAF gene transcription. Alternatively, alterations in the cellular machinery involved in DAF anchorage in membranes could lead to lack of DAF expression. Previous studies $(32,33)$ have shown that DAF is anchored in cell membranes via a carboxy-terminal glycolipid containing inositol phospholipids. This anchoring structure is added to the carboxyterminus of DAF polypeptide during a posttranslational modification that occurs prior to the processing of pro-DAF in the Golgi apparatus (32). Perturbations in the synthesis of this glycolipid unit or in its incorporation into DAF could preclude DAF surface expression. In view of the susceptibility of the glycolipid-anchored protein in some cell types to PI-PLC cleavage $(32,33)$, activation of endogenous PI-PLC enzymatic activity could lead to loss of DAF in some tumor cell lines. However, analyses of culture supernatants of DAF-negative SKMel-1 by IRMA did not reveal immunoreactive DAF molecules. Moreover, hybridization analyses employing DAF cDNA (34) showed that DAF mRNA transcripts were present in HT-144 cells but not in SKMel-1 cells consistent with an effect at the transcription level. Further experiments will provide insights into mechanism(s) operative in DAF nonexpression by other tumors. Whatever these mechanisms, the downregulation of DAF expression could play a facilitory role in tumor surveillance in vivo for some tumors.

In addition to direct tumorcidal actions, complement activation can impact indirectly on tumor growth through effects on vessel permeability, cell trafficking, and possibly sensitization of tumors to cellular effectors. Local formation of C3a can increase both blood flow and diffusion of proteins into tumor containing tissues. The generation of C5a may also increase the influx of phagocytes to tumor sites. The deposition of $\mathrm{iC} 3 \mathrm{~b}$ (or C3b) on target cell surfaces has been demonstrated to promote ADCC activity of lymphocytes (35). The increase in recruitment of effector cells to tumor sites and the enhancement in the efficiency of cell-dependent modalities of tumor killing should contribute to cytotoxicity. In principle, even a partial block in DAF inhibitory function, might result in sufficient activation of the cascade to retard tumor propagation.

The abrogation of DAF function in tumor cells may have clinical implications for targeted immunotherapy using antitumor antibodies. As done in this study, it may be possible to employ tumor specific antibodies in conjunction with antiDAF $F\left(a b^{\prime}\right)_{2}$ fragments to enhance efficiency of tumor killing. However, the clinical usefulness of this approach could be complicated by the limitations that normal tissues could compete effectively for anti-DAF antibodies, that certain tumors may bear amounts of DAF greater than those in normal cells, and that some tumor-selective antibodies can cross react with normal tissues and sensitize them to autologous complement attack if their DAF function is blocked. Furthermore, administration of anti-DAF antibodies could select for tumor variants that show decreased binding to tumor antibodies and increased expression of DAF protein. As an alternative approach, it may be possible in certain tumor types to identify mechanisms other than anti-DAF blocking antibodies, e.g., cytokines, lymphokines, or drugs $(17,18)$, which could selectively downregulate DAF levels or DAF functions.

\section{Acknowledgments}

The authors thank Drs. Melvin Berger and James Jacobberger of Case Western Reserve University for their valuable advice on flow cytometry, and Drs. Lloyd Old and Dr. Allan Houghton of Memorial SloanKettering Cancer Center for supplying the antibody R24 and the cell line SKMel-31.

This work was supported in part by grants from the American Cancer Society (CDA 85-7, RD-226), the National Institutes of Health (CA-39320, AI-24220, AI-23598), the American Heart Association (860975), and the Ireland Cancer Center, Cleveland, $\mathrm{OH}$.

\section{References}

1. Podack, E. R. 1987. Complement and Cytolytic Lymphocytes, Effectors of the Immune Response. E. R. Podack, editor. CRC Press, Boca Raton. In press.

2. Shouval, D., D. A. Shafritz, V. R. Zurawski, K. Isselbacher, and J. R. Wands. 1982. Immunotherapy in nude mice of human hepatoma using monoclonal antibodies against hepatitis B virus. Nature (Lond.). 298:567-569.

3. Capone, P. M., L. D. Papsidero, G. A. Croghan, and T. M. Chu. 1983. Experimental tumoricidal effects of monoclonal antibody against solid breast tumors. Proc. Natl. Acad. Sci. USA. 80:7328-7332.

4. Katano, M., M. Jien, and R. F. Irie. 1984. Human monoclonal antibody to ganglioside $\mathrm{G}_{\mathrm{D} 2}$-inhibited human melanoma xenograft. Eur. Can. Clin. Oncol. 20:1053-1059.

5. Honsik, C. J., and R. A. Reisfeld. 1987. In Cell-mediated Cytotoxicity. J. R. Collins, and B. Bonavida, editors. Alan R. Liss, Inc., New York. In press.

6. Houghton, A. N., D. Mintzer, C. Cordon-Cardo, S. Welt, B. Fliegel, Vadhan S, E. Cardswell, M. R. Melamed, H. F. Oettgen, and L. J. Old. 1985. Mouse monoclonal antibody detecting $G_{D_{3}}$ ganglioside: A phase I trial in patients with malignant melanoma. Proc. Natl. Acad. Sci. USA. 82:1242-1246.

7. Cheung, N. K. V., H. Lazarus, F. D. Miraldi, C. R. Abramowsky, S. Kallick, U. M. Saarinen, T. Spitzer, S. E. Strandjord, P. F. Coccia, and N. Berger. 1987. Ganglioside $G_{D 2}$ specific monoclonal antibody 3F8: a phase I study in patients with neuroblastoma and malignant melanoma. J. Clin. Oncol. 5:1430-1440.

8. Lowder, J. N., T. C. Meeker, and R. Levy. 1985. Monoclonal antibody therapy of lymphoid malignancy. In Cancer Surveys: Advances and Prospects in Clinical, Epidemiological and Laboratory oncology. Vol. 4. Recent Advances in the Treatment and Research in Lymphoma and Hodgkin's Disease. R. Hoppe, editor. Oxford University Press, Oxford. 359-375.

9. Ritz, J., S. E. Sallan, R. C. Bast, J. M. Lipton, L. A. Clavell, M. Feeney, T. Hercend, D. G. Nathan, and S. F. Schlossman. 1982. Autologous bone marrow transplantation in CALLA positive acute lymphoblastic leukemia after in vitro treatment with J5 monoclonal antibody and complement. Lancet. ii:60-63. 
10. Stephen, D. E., R. M. Bartholomew, and T. W. LeBien. 1984. In vitro cytodestruction of human leukemic cells using murine monoclonal antibodies and human complement. Blood. 63:1120-1125.

11. Saarinen, U. M., P. F. Coccia, S. L. Gerson, R. Pelley, and N. K. V. Cheung. 1985. Eradication of neuroblastoma cells in vitro by monoclonal antibody and human complement: method for purging autologous bone marrow. Cancer Res. 45:5969-5975.

12. Bast, R. C., P. DeFabritiis, J. Lipton, R. Gelber, C. Maver, L. Nadler, S. Sallen, and J. Ritz. 1985. Elimination of malignant clonogenic cells from human bone marrow using multiple monoclonal antibodies and complement. Cancer Res. 45:499-503.

13. Gee, A. P., J. Van Hilten, J. Graham-Pole, and M. D. P. Boyle. 1985. Antibody-complement killing of neuroblastoma cells. In Advances in Neuroblastoma Research. A. E. Evan, G. J. D'Angio, and R. C. Seeger, editor. Alan R. Liss Inc., New York. 471-483.

14. Cheung, N. K. V., U. M. Saarinen, J. Neely, B. Landmeier, D. Donovan, P. F. Coccia. 1985. Monoclonal antibodies to a glycolipid antigen on human neuroblastoma cells. Cancer Res. 45:2642-2649.

15. Cahan, L. D., R. F. Irie, R. Singh, A. Cassidenti, and J. C. Paulson. 1982. Identification of a human neuroectodermal tumor antigen (OFA-I-2) as ganglioside $\mathrm{G}_{\mathrm{D} 2}$. Proc. Natl. Acad. Sci. USA. 79:7629-7633.

16. Schultz, G., D. A. Cheresh, N. M. Varki, A. Yu, L. K. Staffileno, and R. A. Reisfeld RA. 1984. Detection of Ganglioside $G_{D 2}$ in tumor tissues and sera of neuroblastoma patients. Cancer Res. 44:5914-5920.

17. Panneerselvam, M., S. Welt, L. J. Old, and C. Vogel. 1986. A molecular mechanism of complement resistance of human melanoma cells. J. Immunol. 136:2534-2541.

18. Panneerselvam, M., R. Bredehorst, and C. Vogel. 1986. Immobilized doxorubicin increases the complement susceptibility of human melanoma cells by protecting complement component $\mathbf{C} 3 \mathrm{~b}$ against inactivation. Proc. Natl. Acad. Sci. USA. 83:9144-9148.

19. Hoffmann, E. M. 1969. Inhibition of complement by a substance isolated from human erythrocytes. I. Extraction from human erythrocyte stromata. Immunochemistry. 6:391-403.

20. Nicholson-Weller, A. J., D. T. Burge, P. F. Fearon, P. F. Weller, and K. F. Austen. 1982. Isolation of a human erythrocyte membrane glycoprotein with decay-accelerating activity for $\mathrm{C} 3$ convertases of the complement system. J. Immunol. 129:184-189.

21. Pangburn, M. K., R. D. Shreiber, and H. J. Müller-Eberhard. 1983. Deficiency of an erythrocyte membrane protein with complement regulatory activity in paroxysmal nocturnal hemoglobinuria. Proc. Natl. Acad. Sci. USA. 80:5430-5434.

22. Medof, M. E., T. Kinoshita, and V. Nussenzweig. 1984. Inhibition of complement activation on the surface of cells after incorporation of decay-accelerating factor (DAF) into their membranes. J. Exp. Med. 160:1558-1578.

23. Kinoshita, T., M. E. Medof, R. Silber, and V. Nussenzweig.
1985. Distribution of decay-accelerating factor in the peripheral blood of normal individuals and patients with paroxymal nocturnal hemoglobinuria. J. Exp. Med. 162:75-92.

24. Nicholson-Weller, A., J. P. March, C. E. Rosen, D. B. Spicer, and K. F. Austen. 1985. Surface membrane expression by human blood leukocytes and platelets of decay accelerating factor, a regulatory protein of the complement system. Blood. 65:1237-1244.

25. Asch, A. S., T. Kinoshita, E. A. Jaffe, and V. Nussenzweig. 1986. Decay-accelerating factor is present on cultured human umbilical vein endothelial cells. J. Exp. Med. 163:221-226.

26. Medof, M. E., E. I. Walter, J. L. Rutgers, D. M. Knowles, and V. Nussenzweig. 1987. Identification of the complement decay-accelerating factor (DAF) on epithelium and glandular cells and in body fluids. J. Exp. Med. 165:848-864.

27. Parker, C. J., P. J. Baker, and W. F. Rosse. 1983. Comparison of binding characteristics of factors $B$ and $H$ to $C 3 b$ on normal and paroxysmal nocturnal hemoglobinuria erythrocytes. J. Immunol. 131:2484-2489.

28. Laemmli, U. K. 1970. Cleavage of structural proteins during the assembly of the head of bacteriophage T4. Nature (Lond.). 227:680-685.

29. Medof, M. E., A. Gottleib, T. Kinoshita, S. Hall, R. Silber, V. Nussenzweig, and W. F. Rosse. 1987. Relationship between decay accelerating factor deficiency, diminished acetylcholinesterase activity, and defective terminal complement pathway restriction in paroxysmal nocturnal hemoglobinuria erythrocytes. J. Clin. Invest. 80:165-174.

30. Bernal, S. D., M. Mabry, R. A. Stahel, J. D. Griffin, and J. A. Speak. 1985. Selective cytotoxicity of the SM1 monoclonal antibody towards small cell carcinoma of the lung. Cancer Res. 45:1026-1032.

31. Zalman, L. S., L. M. Wood, and H. J. Müller-Eberhard. 1986. Isolation of a human erythrocyte membrane protein capable of inhibiting expression of homologous complement transmembrane channels. Proc. Natl. Acad. Sci. USA. 83:6975-6979.

32. Medof, M. E., E. I. Walter, W. L. Roberts, R. Haas, and T. L. Rosenberg. 1986. Decay accelerating factor of complement is anchored to cells by a C-terminal glycolipid. Biochemistry. 25:67406747.

33. Davitz, M. A., M. G. Low, and V. Nussenzweig. 1986. Release of decay-accelerating factor (DAF) from the cell membrane by phosphatidylinositol-specific phospholipase C (PIPLC). Selective modification of a complement regulatory protein. J. Exp. Med. 163:1150-1161.

34. Medof, M. E., D. M. Lublin, D. M. Holers, D. J. Ayers, R. R. Getty, J. F. Leykam, J. P. Atkinson, and M. L. Tykocinski. 1987. Cloning and characterization of cDNA encoding the complete sequence of Decay Accelerating Factor of human complement. Proc. Natl. Acad. Sci. USA. 84:2007-2011.

35. Perlmann, H., P. Perlmann, R. D. Schreiber, and H. J. MüllerEberhard. 1981. Interaction of target cell-bound C3bi and C3d with human lymphocyte receptors. J. Exp. Med. 153:1592-1603. 